\title{
Fed Batch Enzymatic Hydrolysis of Cotton and Viscose Waste Fibers to Produce Ethanol
}

\author{
Kolsum Safartalab ${ }^{1, *}$, Fatemeh Dadashian $^{1}$, Farzaneh Vahabzadeh $^{2}$ \\ ${ }^{1}$ Textile Engineering Department, Amirkabir University of Technology, Tehran, Iran \\ ${ }^{2}$ Chemical Engineering Department, Amirkabir University of Technology, Tehran, Iran \\ *Corresponding Author: kolsum@aut.ac.ir
}

Copyright $(\subseteq 2014$ Horizon Research Publishing All rights reserved.

\begin{abstract}
The main effort of this study was to enhance the enzymatic hydrolysis yields of cotton and viscose waste fibers via fed batch enzymatic hydrolysis. To do so, enzymes fed into slurries at two steps in fed batch mode. Also, the batch mode with the same amount of enzymes was implemented in order to be compared with the fed batch mode. The results showed that the released sugar contents from fed batch hydrolysis of cotton and viscose waste fibers were 29.0 and $32.3 \mathrm{~g} / 1$, respectively, but batch process released 25.0 and $30.3 \mathrm{~g} / 1$ from cotton and viscose waste fibers, respectively, which confirms the increasing effect of fed batch process on the hydrolysis of both waste fibers. In addition, the morphological studies and enzymatic hydrolysis yields from pretreated cotton and untreated viscose waste fibers showed that alkali pretreatment for viscose waste fibers is not necessary, but has significant effect on enzymatic hydrolysis of cotton waste fibers; also, the differences in microcrystalline structures of viscose and cotton waste fibers have resulted in more enzymatic hydrolysis and then fermentation yields of viscose waste fibers. The amount of ethanol produced from cotton and viscose waste fibers were 6.9 and $8.1 \mathrm{~g} / 1$, respectively.
\end{abstract}

Keywords Cotton, Viscose, Cellulosic ethanol, Enzyme

\section{Introduction}

Cellulose is a biocompatible and biodegradable polymer which is widely used in textile industry. Cotton fibers, a sort of cellulosic fibers, have the highest percentage of cellulose among various cellulosic sources [1], and with annual production of more than 23 million tons per year stands for about one third of the global market of textile fibers [2].Viscose fibers, are another cellulose rich fibers, and are commonly used in today's textile industry [3]. These fibers become wasted during the manufacturing and final uses, creating difficulties in the safe disposal of the waste generated $[3,4]$. To overcome such difficulties, there are some works to produce wealth out of such waste fibers by converting them to biogas $[5,6,7,8]$, microcrystalline cellulose [9], cellulosic nanofillers[10], pulps[11], carbon actives[12], as well as ethanol [2, 4, 7, 8, and 13].

Ethanol is currently the most abundant renewable in the global fuel market which is currently produced from sugars, but it is anticipated that the alternative feedstock in the future would be almost certainly lignocellulosic materials [2]. Although cellulosic ethanol could be produced from various sources such as bagasse and other agricultural wastes $[14,15,16]$, but lignin coverage of cellulose in these substrates limits the rate and extend of enzymatic hydrolysis by acting as a shield, restricting enzymatic hydrolysis of digestible regions of substrates[17]; a pretreatment is therefore necessary to disrupt or remove lignin from such substrates, and then increase accessibility of cellulose $[14,15$, $16,18]$, but such pretreatment would increase costs, and complicate the process. Moreover, some of the delignification methods $[16,18]$ have influenced the biocompatibility of the process. As an advantage, cotton and viscose wastes fibers due to lack of lignin in their cellulosic structure [1] won't face with such problems, and thus are suitable substrates for bioethanol production.

Presently, the primary strategy used for cellulosic ethanol production includes three main steps: biomass pretreatment, enzymatic hydrolysis and ethanol fermentation [19]. One of limiting factors in this strategy - in addition to other factors such as recalcitrance of the lignocellulosic biomass [20, 21], sugar inhibition [21], lignin [17] etc. - is enzyme deactivation which plays a significant role in low yields of hydrolysis and thus fermentation[21, 22]; to reduce the effect of this factor, and improve the rate and glucose yield of cellulose hydrolysis, high amount of cellulase and $\beta$-glucosidase is often used, but it remarkably increases costs of the process[23]. So, it is worthwhile to achieve more hydrolysis rate and glucose yield using less enzyme concentration. In relation to this goal, there are some works focused on fed batch enzymatic hydrolysis in which substrates are added at different steps to enhance the hydrolysis yield [24, 25]. In addition, Howell (1987) showed that if the initial enzyme-to-substrate ratio was low, addition of enzymes at later times could make up the deactivated 
enzyme contents in the slurries, led into higher hydrolysis rate [21].

In this work, we attempted to enhance glucose yield from cotton and viscose waste fibers by fed batch enzymatic hydrolysis. For this, enzymes fed into slurries at two steps. Also, in order to investigate the effect of fed batch mode on the hydrolysis yield, the same amount of enzymes was added at the start of hydrolysis in batch mode. The hydrolysates with maximum released sugar contents from each fiber were then fermented to ethanol by Saccharomyces cerevisiae.

\section{Material and Methods}

\subsection{Materials}

The cotton and viscose-based materials used in this article, both containing 100\% cellulose, were Iranian cotton and viscose waste (Lenzing Company) fibers collected from Flyer machine during the spinning of each fiber. Two enzymes, cellulase (Celluclast 1.5L, the best gift from Novozyme) and beta-glucosidase (Novo188) were used for enzymatic hydrolysis. The activity of Celluclast $1.5 \mathrm{~L}$ was measured 127.59 FPU/mL of enzyme solution according to Adney and Baker [26]. The beta-glucosidase activity reported 662 IU/g by supplier. The commercial Baker's yeast (Saccharomyces cerevisiae strain) provided from Iran Mayeh Co. (Iran) was used in the fermentation.

\subsection{Pretreatment Procedures}

At first, samples were washed with commercial detergent for $30 \mathrm{~min}$ at room temperature to remove impurities such as soil and oil. They were then wrung out, rinsed with distilled water and dried at room temperature. Then, the alkali pretreatment was carried out on cotton fibers as described in the previous literature [2]. Briefly, it was carried out with alkali, containing $12 \%(\mathrm{w} / \mathrm{v}) \mathrm{NaOH}$, at room temperature within $3 \mathrm{~h}$ treatment. Also, the fiber-to-liquor ratio was equal to $1: 20$. After this pretreatment cotton fibers were washed with distilled water until $\mathrm{pH} 7$ was obtained. Since viscose fibers are regenerated fibers with high accessibility, they were not pretreated with alkali, and just swelled with distilled water. Pretreated cotton and untreated viscose waste fibers kept in distilled water in a refrigerator for further use. The water was then removed by squeezing samples in time of use. Both pretreated and untreated cotton were used for hydrolysis. The dry weights of fibers before pretreatment have been used for calculations.

\subsection{Batch Enzymatic Hydrolysis}

Saccharification of cotton and viscose waste fibers were separately carried out according to previous literature [2], including enzymatic hydrolysis at $45^{\circ} \mathrm{C}$ and $\mathrm{pH} 4.8$ (with 50 $\mathrm{mM}$ sodium citrate buffer) with $3 \% \mathrm{w} / \mathrm{v}$ solid substrates and $150 \mathrm{rpm}$ in the presence of the enzymes cellulase $20 \mathrm{FPU} / \mathrm{g}$ substrate and beta-glucosidase $30 \mathrm{IU} / \mathrm{g}$ substrate.

\subsection{Fed Batch Enzymatic Hydrolysis}

The fed batch hydrolysis condition was similar to batch condition except that only $30 \%$ of the total concentrations of enzymes were added at the start of the process, and the residual amount of enzymes was added at $24^{\text {th }}$ hour to get the final enzymes concentrations of cellulase $20 \mathrm{FPU} / \mathrm{g}$ substrate and beta-glucosidase $30 \mathrm{IU} / \mathrm{g}$ substrate.

\subsection{Fermentation of Hydrolysates}

The hydrolysates with maximum glucose contents from each fiber were selected to be fermented to ethanol. At first, they were neutralized with calcium hydroxide $\left(\mathrm{Ca}(\mathrm{OH})_{2}\right)$, and then centrifuged at $5000 \mathrm{rpm}$ for $15 \mathrm{~min}$. After that, the supernatants supplemented with $(\mathrm{g} / \mathrm{l})$ : soya peptone, 5; $\left(\mathrm{NH}_{4}\right)_{2} \mathrm{SO}_{4}, 7.5 ; \mathrm{K}_{2} \mathrm{HPO}_{4}, 3.5 ; \mathrm{MgSO}_{4} \cdot 7 \mathrm{H}_{2} \mathrm{O}, 0.75 ; \mathrm{CaCl}_{2}, 1$. Then $0.15 \mathrm{~g}$ of the dry commercial yeast Saccharomyces cerevisiae, as an inoculum, was added to $20 \mathrm{~mL}$ hydrolysates, and finally the slurries were fermented at $29^{\circ} \mathrm{C}$ for 2 days.

\subsection{Analytical Methods}

The ethanol concentrations of resulting supernatants were analyzed by high performance liquid chromatography (HPLC) after filtration through a $0.45 \mu \mathrm{m}$ syringe filter. HPLC was employed equipped with a Waters 515 HPLC pump, Waters 2410 refractive index detector fitted with a Sugar-Pak1 column with an inner diameter of $6.5 \times 300 \mathrm{~mm}$. The supernatants were eluted with water at a flow rate of $0.35 \mathrm{ml} / \mathrm{min}$. Also, the amount of reducing sugars presented in supernatants was determined by DNS method. The microstructures of waste fibers before and after pretreatment were investigated by Fourier transform infrared (FTIR) spectroscopy. All the experiments, except for FTIR and HPLC spectra, were performed in duplicate. All the results are presented as averages. The average standard deviation of the results was less than $9.8 \%$.

\section{Results and Discussion}

\subsection{Alkali Pretreatment and Morphological Studies}

For cotton waste fibers, cellulosic structures of waste fibers before and after pretreatment are investigated with the help of FTIR spectra, shown in Fig.1. The wide peak 3405 $\mathrm{cm}^{-1}$ at 3000-3800 $\mathrm{cm}^{-1}$ region observed for cotton waste fibers before and after pretreatment is ascribed to stretching motion of intra-molecular hydrogen bonds which is related to cellulose I. The intensity observed at the peak $1635 \mathrm{~cm}^{-} 1$, related to the adsorbed moisture $\left(\mathrm{H}_{2} \mathrm{O}\right)$, was stronger for pretreated cotton in comparison with untreated cotton waste fibers; it can be due to the larger surface area of pretreated cotton waste fibers resulted from swelling of fibers during 
pretreatment. Also, the peak at $1430 \mathrm{~cm}^{-1}$ for FTIR spectra of both untreated and pretreated cotton waste fibers is attributed to crystallized cellulose I [27]; these observations confirmed that microstructure of cellulose just swelled, and no crystalline structure changes after pretreatment of cotton waste fibers.

The total crystallinity (TCI) and lateral order (LOI) indices, presented by Nelson and O'Connor [28, 29], were used to study crystallinity changes after pretreatment (Tables 1). As shown in Table 1 , it is revealed that there is nearly a noticeable decrease in the LOI ratios, from 2.12 to 2.58 for cotton fibers, confirming reducing crystallinity after pretreatment of cotton waste fibers; maybe swelling of amorphous regions is the reason of this lower total crystallinity.

Table 1. Infrared crystallinity indices data on cotton waste fibers before and after pretreatment.

\begin{tabular}{ccc}
\hline Condition & $\begin{array}{c}\text { Lateral crystallinity } \\
\text { index(LOI) } \\
(1430 / 900)\end{array}$ & $\begin{array}{c}\text { Total crystallinity } \\
\text { index(TCI) } \\
(1375 / 2900)\end{array}$ \\
$\begin{array}{c}\text { Untreated } \\
\text { cotton }\end{array}$ & 2.12 & 0.97 \\
\hline $\begin{array}{c}\text { Pretreated } \\
\text { cotton }\end{array}$ & 2.58 & 0.90 \\
\hline
\end{tabular}

Furthermore, the FTIR spectrum of untreated viscose waste fiber, shown in Fig.1, revealed peaks attributed to cellulose II: the peak at $1420 \mathrm{~cm}^{-1}$; the wide peak at 3440 $\mathrm{cm}^{-1}$ between $3000-3800 \mathrm{~cm}^{-1}$, showing the stretching motion of intra-molecular hydrogen bonds between cellulose chains; the peak at $895 \mathrm{~cm}^{-1}$, showing the frequency of carbon-1 group in cellulose chains; these peaks confirmed that the cellulosic structure of viscose waste fibers was cellulose II [27].

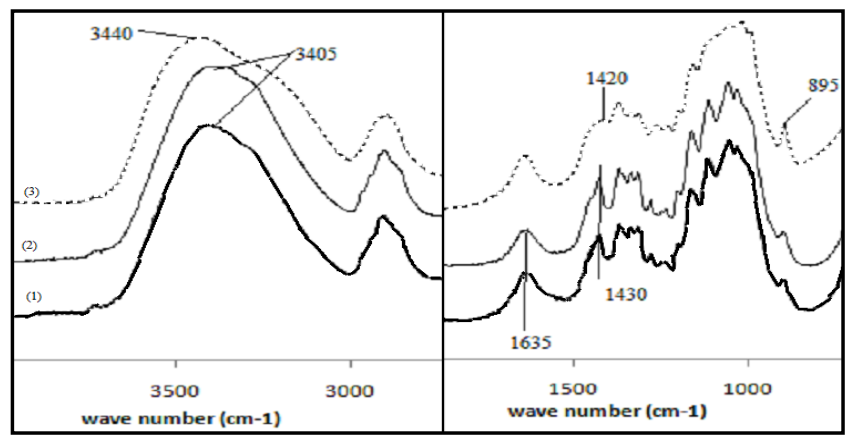

Figure 1. FTIR spectra of cotton waste fibers before (1) and after (2) pretreatment, and FTIR spectrum of untreated viscose waste fibers (3).

\subsection{Hydrolysis Rate during Different Times}

By comparison of hydrolysis yield before and after pretreatment, it is revealed that the pretreatment has significant effect on the hydrolysis of cotton waste fibers, but has negligible effect on the hydrolysis of viscose waste fibers (Table 2). The reason is maybe using higher concentration of alkali on cotton waste fibers (12\%) than that treated on viscose waste fibers $(1 \%)$, so more hydrogen bonds, restricting the access of enzymes to $\beta$-1,4-glycosidic bonds and other functional groups in cellulose, were cleaved within cotton waste fibers [8]. On the other hand, using more alkali concentration on viscose waste fibers caused weight loss on fibers (Table 3), decreasing subsequent enzymatic hydrolysis yield. Thus, viscose waste fibers were used in wet state and before alkali pretreatment for further studies to reduce process costs. That is, swelling of viscose waste fibers with just distilled water is an effective pretreatment method.

Table 2. Theoretical hydrolysis yield and ethanol production of cotton and viscose waste fibers from batch and fed batch enzymatic hydrolysis.

\begin{tabular}{cccccc}
\hline Waste fibers type & $\begin{array}{c}\text { Batch mode } \\
(\mathbf{g} / \mathbf{l})\end{array}$ & $\begin{array}{c}\text { Batch mode yield } \\
\mathbf{( \% )}\end{array}$ & $\begin{array}{c}\text { Fed batch mode } \\
(\mathbf{g} / \mathbf{l})\end{array}$ & $\begin{array}{c}\text { Fed batch mode yield } \\
(\mathbf{\%})\end{array}$ & $\begin{array}{c}\text { Ethanol } \\
(\mathbf{g} / \mathbf{l})\end{array}$ \\
\hline Untreated cotton & 18.77 & 56.4 & ---- & --- & --- \\
Pretreated cotton & 25.0 & 75.1 & 29.0 & 87.1 & 6.90 \\
Untreated viscose & 30.3 & 91.0 & 32.3 & 97.0 & 8.10 \\
Pretreated viscose & 30.55 & 91.7 & --- & --- & -- \\
\hline
\end{tabular}

Table 3. The weight loss of the fibers occurred by the alkaline pretreatment of viscose waste fibers with different concentrations of $\mathrm{NaOH}$.

\begin{tabular}{cccc}
\hline Alkali concentration (w/v)\% & Weight before alkali treatment $(\mathbf{g})$ & Weight after alkali treatment(g) & Weight loss (\%) \\
\hline 2 & 0.31 & 0.30 & 3.2 \\
5 & 0.33 & 0.22 & 33.3 \\
9 & 0.32 & 0.16 & 50.0 \\
12 & 0.30 & 0.07 & 76.7 \\
\hline
\end{tabular}


Utilizing wet fibers at the start of hydrolysis which causes swelling into amorphous regions facilitates diffusion of cellulase into amorphous region, and also, increases the surface area for hydrolysis [20], lead to high initial hydrolysis rate confirmed by Fig. 2\&3; furthermore, the existence of higher amount of fresh enzymes which has not been deactivated yet could be the cause of high initial hydrolysis rate [21]; this could be confirmed by comparison of initial rate of fed batch and batch hydrolysis for both waste fibers because initial hydrolysis rates for batch mode are more than those of fed batch mode which could be attributed to higher concentration of enzymes at the start of hydrolysis in batch mode.

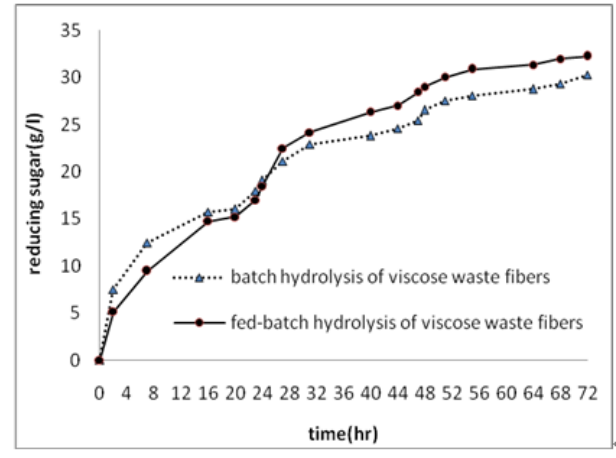

Figure 2. Comparison of batch and fed batch hydrolysis rates of viscose waste fibers.

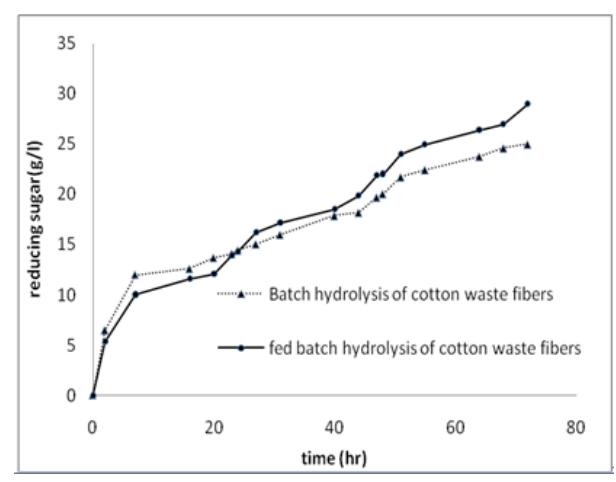

Figure 3. Comparison of batch and fed batch hydrolysis rates of cotton waste fibers.

During enzymatic hydrolysis, digestion of amorphous regions increases the proportion of crystalline regions in substrates and then resistance against hydrolysis $[20,21]$. Moreover, deactivation of enzymes due to product inhibition and other processes (i.e. denaturation of enzymes by heat) [21] is another resistance against hydrolysis, resulted into plateau part of the curves for batch hydrolysis of both waste fibers.

In addition, according to Fig. $2 \& 3$, using fresh enzymes in fed batch mode could make up the reduced rates for both fibers, and then resulted into higher hydrolysis yield (Table 2) which is in accordance with Howell's finding [21] which says that if the initial enzyme-to-substrate ratio was low, resuspension of substrate in fresh enzyme or addition of fresh enzyme resulted into further high rate hydrolysis [21].
Although the initial rate in fed batch mode was lower than that in batch mode, Fig $2 \& 3$, the hydrolysis rate become higher after $24 \mathrm{~h}$ when the residual fresh enzymes were added into the fed batch mode. This rapid increase in hydrolysis rate could be attributed to addition of fresh enzymes that makes up the deactivated enzymes contents in the slurries.

As shown in Table 2, the hydrolysis, and thus ethanol yields for viscose are more than those of cotton waste fibers. This can be explained by the crystalline structure of viscose waste fibers, cellulose II, compared with the crystalline structure of cotton waste fibers, cellulose I; in fact, parallel arrangement of the chains in cellulose I forms hydrogen-bonded sheets that stack through hydrophobic interaction resulted into no hydrogen bonds between the sheets, but nonparallel arrangement of the chains in cellulose II causes sheets to stacked through hydrophobic interaction and further stabilizing with intermolecular hydrogen bonds. During hydrolysis, hydrophobic attraction would act as a main obstacle in enzymatic hydrolysis, while hydrogen bonds in the first layer of cellulose crystallites could become unstable in water. Therefore, converting cellulose I into cellulose II would weaken the internal hydrophobic interaction, and thus it could enhance enzymatic hydrolysis rate [30]. Furthermore, lower crystallinity of viscose waste fibers, which is about $40 \%$ [31], compared with cotton waste fibers, which has about $60 \%$ crystallinity [31], facilitates the digestion of viscose waste fibers with the enzymes.

\section{Conclusion}

This study proved that fed batch enzymatic hydrolysis of cotton and viscose waste fibers improved the release of sugars and subsequently ethanol yields. The results showed that the fed batch hydrolysis of cotton and viscose waste fibers released $29.0 \mathrm{~g} / 1$ and $32.3 \mathrm{~g} / 1$ sugars, respectively, but the batch mode of enzymatic hydrolysis of both fibers released $25.0 \mathrm{~g} / 1$ and $30.3 \mathrm{~g} / 1$ sugars, respectively.

Furthermore, the advantages of viscose compared with cotton waste fibers are their cellulosic structure, which is cellulose II, and their lower crystallinity, resulted into easier digestion, and then more hydrolysis and ethanol yields of viscose waste fibers. In addition, although the highly crystalline structure of cotton waste fibers makes them difficult to digest by enzymes, alkali pretreatment reduced crystallinity, and then increased the hydrolysis yield. Although, this work revealed the increasing effect of fed batch mode on enzymatic hydrolysis and then ethanol yields, optimization of fed batch process and find a best pattern for addition of enzymes should be investigated in future studies.

\section{REFERENCES}

[1] Miranda R., Sosa-Blanco C., Bustos-Martinez D., Vasile C., 
"Pyrolysis of textile wastes: I. kinetics and yields", J.Anal. Appl. Pyrolysis, Vol.80, No.2, (2007), 489-495,

[2] Jeihanipour A., Taherzadeh M.J., "Ethanol production from cotton-based waste textiles", Biortech, Vol.100, (2009), 1007-1010.

[3] Woodings C., "Regenerated cellulose fibres, Woodhead and CRC Press", USA \& England, (2001), 37-38.

[4] Arthe R., Rajesh R., Rajesh E.M., Rajendran R., Jeyachandran S., "Production of bio-ethanol from cellulosic cotton waste through microbial extracellular enzymatic hydrolysis and fermentation", EJEAFChe, Vol.7, No.6, (2008), 2984-2992.

[5] Demirer G.N., Isci A., "Biogas production potential from cotton wastes", Renene, Vol.32, No.5, (2007), 750-757.

[6] Macias-Corral M.A., Samani Z.A., Hanson A.T., DelaVega R., Funk P.A., "Producing energy and soil amendment from dairy manure and cotton gin waste", ASAE, Vol.48, No.4, (2005), 1521-1526.

[7] Jeihanipour A., Karimi K., Niklasson C., Taherzadeh M.J., "A novel process for ethanol or biogas production from cellulose in blended-fibers waste textiles", Wasman, Vol.30, (2010), 2504-2509.

[8] Jeihanipour A., Karimi K., Taherzadeh M.J., "Enhancement of ethanol and biogas production from high-crystalline cellulose by different modes of NMO pretreatment", Biotechnology and Bioengineering, (2009).

[9] Ray D., Das K., Bandyopadhyay N.R., Ghosh T., Mohanty A.K., Misra M.A., "Study of the mechanical, thermal and morphological properties of microcrystalline cellulose particles prepared from cotton slivers using different acid concentration", Cellulose, Vol.16, (2009), 783-793.

[10] Teixeira E.D., Correa A.C., Manzoli A., Leite F.D., De Oliveira C.R., Mattoso L.H.C., "Cellulose nanofibers from white and naturally colored cotton fibers", Cellulose, Vol.17, No.3, (2010), 595-606

[11] Dadashian F., Shojaiee K.m., "Recycling of cellulosic fibers by enzymatic process", Appl. Biochem. Biotechnol, Vol.166, No.3, (2012), 744-749.

[12] Hernandez J.R., Aquino F.L., Capareda S.C., "Activated carbon production from pyrolysis and steam activation of cotton gin trash", ASABE Annual International Meeting, Minneapolis, Minnesota, (2007), 17- 20 June.

[13] Mahalakshmi M., Angayarkanni J., Rajendran R., Rajesh R., "Bioconversion of cotton waste from textile mills to bio ethanol by microbial saccharification and fermentation", Ann Appl Biol, Vol.2, No.3, (2011), 380-388.

[14] Kaparaju P., Serrano M., Belinda Thomsen A., Kongjan P., "I. Angelidaki. Bioethanol, biohydrogen and biogas production from wheat straw in a biorefinery concept", Biortech, Vol.100, (2009), 2562-2568.

[15] Karimi K., Emtiazi G., Taherzadeh M.J., "Production of ethanol and mycelial biomass from rice straw hemicellulose hydrolyzate by Mucor indicus", Procbio, Vol.41, (2006), 653-658.

[16] Zhao X., Wu R., Liu D., "Production of pulp, ethanol, and lignin from sugarcane bagasse by alkali-peracetic acid delignification", Biombioe, Vol.35, No.7, (2011), 2874
2882.

[17] Hendriks A.T.W.M., Zeeman G., "Pretreatments to enhance the digestibility of lignocellulosic biomass", Biortech, Vol.100, No.1, (2009), 10-18.

[18] Karimi K., Emtiazi G., Taherzadeh M.J., "Ethanol production from dilute-acid pretreated rice straw by simultaneous saccharification and fermentation with mucor indicus, rhizopus oryzae, and saccharomyces cerevisiae", Emt, Vol.40, No.1, (2006), 138-144.

[19] Gupta R., Kumar S., Gomes J., Chander Kuhad R., "Kinetic study of batch and fed batch enzymatic saccharification of pretreated substrate and subsequent fermentation to ethanol", Biotechnology for Biofuels, (2012), 5-16.

[20] Arumgam K., "Enzymatic treatment of fibers for nonwovens", MSC thesis, North Carolina state university, (2005).

[21] Howell J.A., "Enzyme deactivation during cellulose hydrolysis", Biotechnology and Bioengineering, xxx, (1978), 847-863.

[22] Chena M., Xiaa L., Xue P., "Enzymatic hydrolysis of corncob and ethanol production from cellulosic hydrolysate", Ibiod, Vol.59, (2007), 85-89.

[23] Zheng Y., Pan Z., Zhang R., Wang D., "Enzymatic saccharification of dilute acid pretreated saline crops for fermentable sugar production", Applied Energy, Vol.86, (2009), 2459-2465.

[24] Chander Kuhad R., Mehta G., Gupta R., Kant Sharma K., "Fed batch enzymatic saccharification of newspaper cellulosics improves the sugar content in the hydrolysates and eventually the ethanol fermentation by Saccharomyces cerevisiae", Biombioe, xxx, (2010), 1-6.

[25] Rudolf A., Akasrawi M., Zacchi G., Liden G., "A comparison between batch and fed batch simultaneous saccharification and fermentation of straw pretreated spruce", Enz Microb Technol, Vol.37, (2005), 195-204.

[26] Adney B., Baker J., "Measurement of Cellulase Activities", LAP-006 NREL Analytical Procedure Golden CO., (1996).

[27] Carrillo F., Colom X., Sunol J.J., Saurina J., "Structural FTIR analysis and thermal characterization of lyocell and viscose-type fibers", Europolj, Vol.40, (2004), 2229-2234.

[28] Nelson ML., O’Connor RT., "Relation of certain infrared bands to cellulose crystallinity and crystal lattice type Part I. spectra of lattice types I, II, III and amorphous cellulose", J.Appl Polym Sci, Vol.8, (1964), 1311-1324.

[29] Nelson ML., O'Connor RT., "Relation of certain infrared bands to cellulose crystallinity and crystal lattice type. Part II. a new infrared ratio for estimation of crystallinity in cellulose I and II", J.Appl Polym Sci, Vol.8, (1964), 1325-1341.

[30] Wada M., Ike M., Tokuyasu K., "Enzymatic hydrolysis of cellulose I is greatly accelerated via its conversion to the cellulose II hydrate form", Polymer Degradation and Stability, Vol.95, (2010), 543-548.

[31] Fourne F., "Synthetic Fibers: Machines and Equipment, Manufacture, Properties Handbook for Plant Engineering, Machine Design, and Operation", Hanser Gardner Pubns, (1999), p2. 